\title{
A Case for Accelerated Education - Student Empowerment and Agency
}

\author{
Sakina Rizvi \\ Department of Integrated Studies in Education \\ McGill University, Canada
}

\begin{abstract}
Researchers have published various empirical studies on the veracity of accelerated learning models. Most studies attest to the effectiveness of accelerated learning and highlight the importance of providing students with a nurturing environment to explore and pursue accelerated learning options. However, there is still significant resistance to accelerated learning due to social norms and conceptions about normality, success, and achievement. In the 1970s and 1980s, acceleration was a relatively new phenomenon. Recent scholarship in the field has addressed many of the concerns raised by educational policy makers and teachers about the socio-behavioural impact of accelerated learning. Although the evidence is overwhelmingly positive for acceleration, students who try to learn at a faster pace continue to encounter significant systemic and institutional barriers. To create an inclusive learning environment for all students, educators need to be willing to open the space for alternative pathways for achievement. It is possible to create a brighter future for students by engaging in holistic pedagogy that allows learners to adopt an agentic role in selecting their learning pace.
\end{abstract}

\section{Introduction}

Dr. Georgi Lozanov is often credited as the founder of accelerated education in North America. In the 1970s, he published various articles on challenging students' learning potential and engaged in innovative teaching practices to help students learn content at a faster pace [3]. In the last couple of decades, several researchers and practitioners developed Lozanov's pedagogical techniques for increasing students' retainment of content and used his work as the basis for developing accelerative and alternative learning models for students [2]. Lozanov argued for re-envisioning teaching methodologies that are centred around rote memorization and mechanical forms of learning that do not build students' critical thinking skills [3]. Such approaches do not challenge learners to engage with content in an immersive manner. As a result, students may develop behavioural challenges and a negative attitude towards education [2], [10], [13]. Lozanov's approach was revolutionary as it challenged traditional pedagogies based on hierarchical methods of learning [3].

Lozanov believed that existing pedagogical practices in the 1970s did not maximize the capacity of the human mind [3]. He felt that there was a disconnect between traditional teaching strategies and literature on the development and potential of the brain [3]. Traditional practices limited students' abilities by restricting their access to accelerated education pathways [2], [4], [10]. Lozanov thought that it was possible to help students become more engaged in their learning by focusing on creating a supportive learning environment that would push them to learn at a faster pace [3]. In later years, many of Lozanov's theories about students' capacity and learning abilities were corroborated in other studies [4], [2], [9]. Learners are trained to believe that they can only absorb information at the pace dictated by educational authorities [3]. Through explicit and implicit forms of instruction, many students internalize the idea that their learning capacity and ability is unchangeable and must conform to standardized requirements. Lozanov argued that such an approach causes many learners to be affected by "school neurosis" [3]. These learners do not believe in their ability to excel beyond curricular standards and undergo a traumatic educational experience. Many educators may also unconsciously strengthen students' defeatist attitude towards education if they are convinced that the student must adhere to traditional schooling expectations [3]. As a result, they may feel that they are protecting learners by limiting their opportunities to learn at a faster pace or access more challenging content. Some educators have tried to address the needs of accelerated students by giving them the freedom to learn independently during course lessons [3]. However, such an approach is ineffective as it does not provide the learner with the option to learn at a faster pace and strengthens the notion that they are inadequately prepared and incapable of accelerating [3]. Students internalize this inadequacy when they face systemic barriers for vocalizing their desire to accelerate [2], [3]. Providing students with the freedom to access challenging content within subjects is a short-term solution and is not as effective as acceleration [3]. Lozanov 
illustrated his view on this issue and mentioned the following [3]:

"If a teaching system succeeds in freeing the pupil from his fear and acceptance of the social norm that suggests that his capacities are limited, it will then find that the other educational objectives can be easily attained. The main difficulty consists not so much in giving the pupil a sense of freedom in the initial stage of his education as in setting up a system that will ensure lasting freedom. Not only must the pupil rid himself of his defeatist attitude; he must also continue to be sure that such an attitude is unfounded...In this way, education will reach beyond the limits suggested by the accepted social norm and will be able to tap the infinite potential of the human personality" (p.417).

Lozanov advocated for a widescale reform of pedagogical practices and policies that limited students' autonomy and caused learners to undergo self-doubt and anxiety [3]. He believed that it was critical for educators to deconstruct social norms that structured exclusionary standards. Several researchers have also argued that learning styles and ability levels are not fixed and can increase or decrease depending on a variety of external factors [3], [18], [19]. In an educational context, this would include the learning environment, pedagogical approaches, teacher support, and peer relationships. Educators have a lot of power in creating a space that is emotionally, socially, and physically safe for students. If students feel comfortable in their learning environment, they are more likely to take the initiative to access opportunities for growth and development [8], [16]. Teachers play an influential role in helping students look beyond social norms and institutional policies that prevent learners from exceeding standardized conceptions of success [3]. However, educators must be willing to reconceptualize ideas that limit students' growth based on their age. Accelerated learning programs allow students to complete their educational requirements at a faster pace and do not rigidly correlate age with intellectual potential for all learners [11]. There are various forms of acceleration in the form of grade-skipping, early entrance to postsecondary learning spaces, split classes, and partial subject based acceleration [2]. Accelerated learning programs are not suitable for all students, but there are learners who need accelerative programs for their social and emotional well-being. Educators can develop students' learning capacity by building a collaborative relationship with them through dialogue and discussion about alternative educational pathways.

\section{Accelerated Students' Experiences}

When the idea of accelerated learning was introduced, educators had access to a limited number of studies that tested the effectiveness of accelerated education programs. However, over the last couple of years, the field of accelerated education has advanced, and researchers have been able to conduct several empirical studies on the topic [4], [5], [6], [9], [10]. A significant report on this issue titled, A Nation Deceived: How Schools Hold Back America's Brightest Students. The Templeton National Report on Acceleration was released in 2004 and provided the wider public with a comprehensive analysis of accelerated learning models. In this report, the researchers argued that acceleration is critical for the development of many students [2]. There are various misconceptions about the purpose and impact of accelerative programs, despite research that demonstrates the necessity for accelerated learning options based on students' socio-behavioural and academic needs [4], [8], [14]. Most learners benefit from accelerative programs with increased levels of confidence and motivation for learning content [2], [4], [13]. Accelerative learning options are also economical and do not require school administrators to allocate large amounts of government funding to support the needs of accelerated students [2]. For instance, offering a learner the option to skip a grade if they are emotionally, socially, and academically ready may simply mean placing a desk for the student in the classroom that adequately suits their learning pace [2]. For parents, accelerative learning options can also be beneficial as they remove the need to enrol children in enrichment programs and extra-curricular camps. Parents often resort to such options to address their children's disengagement and need for a higher challenge [2]. However, placing a child in the right classroom environment is a simpler solution that would provide learners with the appropriate stimulation. There are financial benefits of accelerative learning options for parents, educators, and administrators, but the primary need for accelerated learning programs is based on the wellbeing of students who are negatively impacted by a rigid segregation process [2], [10]. Unfortunately, many learners do not have access to accelerated learning options. They are unable to find a place for themselves in the education system and develop behavioural challenges [2], [6]. They do not feel stimulated in classes and are unable to find pathways for growth [10]. Often, their desire to learn at a faster pace is rejected by educational administrators and their families are told that they do not have an understanding about what is right for their child [2]. Year after year, these children encounter challenges, but their needs are ignored. They are told to stay in their place within the system and discouraged from pursuing higher goals. If educators are committed to helping students achieve excellence, they need to allow students to challenge social norms and explore pathways that address their needs. In the last couple of years, researchers have conducted longitudinal studies with accelerated learners to understand how 
acceleration impacts their development [4]. A recent study titled, Academic acceleration in gifted youth and fruitless concerns regarding psychological wellbeing: A 35-year longitudinal study, was conducted to understand the effect of acceleration on the psychological well-being of students [4]. The researchers wanted to understand whether accelerative interventions for youth resulted in negative long-term consequences. They tracked three cohorts of students for over 35 years and explored the correlation between their choice to accelerate and their psychological well-being at age 50. The researchers found that the participants did not encounter any psychological challenges because of their choice to accelerate and their findings corroborated previous studies that illustrated the positive effect of acceleration on precocious youth [4]. Participants did not have major regrets about accelerating, and many wished that they would have accelerated more during their adolescence. The participants that were studied had an appropriate amount of support from their families in their journey as accelerated students [4]. The results of the study provide evidence for the effectiveness of accelerative inventions and highlight the connection between acceleration and future professional and personal achievements. The researchers reported that their findings do not support the general perception regarding the negative impact of acceleration on the socio-emotional growth of learners [4]. Although many educators and families worry about placing a child in an accelerated class, they also need to consider the impact of placing a child in a learning environment that does not challenge or engage them.

\section{Dialogue, Discussion, and Exploration}

As educators strive towards creating a more inclusive and holistic learning environment for students, it is critical to open the space for exploring alternative learning models. Although there is a lot of work that has been done in the field of accelerated learning, there are still some areas of concern that need to be explored further [14]. As researchers continue to explore these areas, educators also need to be mindful about current challenges with rigid understandings of success, capacity, and ability. Accelerated students must fight an uphill battle to be valued at the same level as their peers. These students encounter discouraging attitudes from academics, scholars, and policy makers in positions of power [14], [16], [17]. Some educators believe that accelerated students do not require support and dismiss their need for more program options. Researchers have reported on the unsupportive attitudes of preservice teachers towards acceleration and have outlined the various ways that practitioners resist efforts to offer more services to accelerated learners [16]. These educators strengthen social myths about acceleration without an understanding of the empirical evidence or literature on the topic [2]. Teachers may project their personal beliefs about acceleration through derogatory comments and exclusionary practices that do not create a nurturing learning environment. Many accelerated learners are involved in a variety of social activities in the form of sports clubs, community organizations, and youth events. Their choice to accelerate does not stifle their growth, rather, it strengthens their self-concept and ability to perform at the highest level. An accelerated learner must develop perseverance to resist standardized understandings of the optimal learning environment, pace, and experience. Educators need to create spaces of dialogue and discussion with accelerated students, as many do not have an understanding about their learning needs [14].

\section{Implicit and Explicit Bias}

Variety of studies shows that teachers' beliefs about students' abilities influences their understanding of what they can achieve [5], [12], [15], [20]. It is critical for educators to be mindful about ensuring that personal biases do not limit students' opportunities. Implicit and explicit forms of bias towards a particular method or model of learning may exclude students who require another path. In a teacher-student relationship, students are in a vulnerable position due to their lower level of authority. Educators who prevent students from accelerating due to their personal bias need to reflect on their use of power. There are various ways that teachers can help learners who need an accelerated learning environment. Firstly, teachers need to ensure that students feel safe in voicing their desire to accelerate. Educators should support learners who take the initiative to share their academic concerns. There are systemic barriers that may prevent a student from accelerating, but a teacher is often the primary figure of trust and support for students. Accelerated students need advocates who can represent and share their needs in the presence of educational policy administrators. If a teacher has the power to open the way for a student to accelerate and refuses to do so, they need to consider the impact of limiting options for students who are in vulnerable positions. Teachers can only advocate for accelerated learners if they are willing to reconceptualize their understanding of accelerated students and seek opportunities to gain insight about the best way to support their needs [2]. Learners are deeply impacted by the prejudices and misconceptions held by educators and administrators and cannot escalate a disagreement to a positive resolution. Some educators may feel that nonacceleration is a safer and more neutral option. However, preventing students from accelerating is an intervention that can have significant negative repercussions [2]. Neutrality would require educators 
to be willing to support non-accelerated and accelerated students. Although various researchers have reported on the positive socio-behavioural impact of acceleration and have recounted the narratives of students who had no struggle adjusting in a post-secondary environment, there is an absence of learning spaces that reflect the evidence on the efficacy of accelerated learning options [2], [4], [14]. Implicit and explicit forms of bias stagnate growth and prevent educational reform. Often, teachers do not have a comprehensive understanding of accelerated education models and are unable to access professional development opportunities that address the topic [5], [16]. Educational administrators need to support teachers who require more training for catering to the needs of accelerated students. However, in the absence of such resources, educators need to tackle the root of the hesitancy or discomfort they feel towards acceleration. If teachers disagree with accelerated learning models at a conceptual level, they need to consider the results of a large collection of studies that attest to the effectiveness and need for accelerated learning programs [2], [3], [4], [8], [9]. Some educators may feel that age is the best determinant of intellectual capacity and oppose accelerated learning options due their belief that such programs would have a negative socio-behavioural impact on students. This may be true for some learners, but educators need to consider other measures for determining intellectual potential in cases where a student is academically, socially, and behaviourally ready for acceleration. If teachers are concerned that learners will encounter developmental gaps because of their choice to accelerate, they need to reflect on the literature which shows that accelerated students are quick learners and require acceleration due to their advanced level of knowledge [2]. Lastly, if educators feel that non-acceleration is a safer option or that acceleration pushes learners beyond their capacity, they also need to analyze the evidence that outlines the long-term consequences of not addressing the academic and social needs of accelerated students [2], [3]. Many learners become disengaged from school and may find negative ways to channel their energy [10]. As a result, these students can create a variety of challenges for educators and may be asked to leave an academic institution. A behavioural issue could provoke an expulsion, but the root of the problem may be centered around the absence of an accelerated education program. Educators should not homogenize students' learning needs and must recognize individual learning differences. Implicit and explicit forms of bias create unsettling and exclusionary learning spaces that limit students' growth and development.

\section{Conclusion}

To create a learning environment that is empowering for all students, teachers must be willing to re-evaluate their beliefs and perspectives. As educators commit themselves to the process of continual learning, they need to adapt and change their teaching methodologies when there is evidence for the efficacy of an alternative instructional model. Without this commitment, it is difficult to materialize the cutting-edge scholarship that researchers have published [4]. The current education model works for many students, but there are systemic changes that need to be implemented to support learners who require alternative educational pathways that do not consider age as the sole criteria for determining intellectual potential. Secondly, administrators and policy makers must avoid generalizations in their professional judgments and decisions. All students cannot be painted by the same brush and generalized assumptions that characterize all students by the same measure, limit progress [2]. Acceleration should not be forced on any student, but it should not be banned for every student. Rigid approaches to acceleration do not allow educators to target the group of students that are in most need of accelerated learning, and only serve to mischaracterize the reality of the situation. Students need to be provided with a more agentic role in their education and should feel safe about vocalizing their requirements and goals. Often, discussions about policy change and learning models happen at the level of educational administration, but the students who are most impacted by these discussions are not given a voice in the decisionmaking process. Educators need to be willing to build a collaborative relationship with students to empower them to choose the educational model that is best for them. If educators and administrators are truly committed to excellence, they need to provide more options for students who feel excluded in the current education system. Without alternative pathways, it is very difficult for students to overcome systemic hurdles that limit their growth. By providing students with the tools for maximizing their potential, it is possible to create a brighter and more inclusive future for every learner.

\section{References}

[1] Cooke, S., (2018). The creative classroom environment. Journal of Classroom Interaction, 53(2), 62-76.

[2] Colangelo, N., and National Association for Gifted Children (U.S.). (2004). A Nation Deceived: How Schools Hold Back America's Brightest Students (Vol. V. and V.II). University of Iowa.

[3] Lozanov, G., (1979). Accelerated learning and individual potential. Prospects, 9(4), 414-425. 
[4] Bernstein, B. O., Lubinski, D., and Benbow, C. P., (2021). Academic acceleration in gifted youth and fruitless concerns regarding psychological well-being: A 35-year longitudinal study. Journal of Educational Psychology, $113(4), 830-845$

[5] Hoogeveen, L., van Hell, J. G., and Verhoeven, L., (2005). Teacher attitudes toward academic acceleration and accelerated students in the Netherlands. Journal for the Education of the Gifted, 29(1), 30-59.

[6] Ma, X., (2003). Effects of early acceleration of students in mathematics on attitudes toward mathematics and mathematics anxiety. Teachers College Record, 105(3), 438-64.

[7] Laine, S., Hotulainen, R., and Tirri, K., (2019). Finnish elementary school teachers' attitudes toward gifted education. Roeper Review, 41(2), 76-87.

[8] Lee, S.-Y., Olszewski-Kubilius, P., and Peternel, G., (2010). The efficacy of academic acceleration for gifted minority students. Gifted Child Quarterly, 54(3), 189-208.

[9] Gross, M. U. M., and Van Vliet, H.E., (2005). Radical acceleration and early entry to college: A review of the research. The Gifted Child Quarterly, 49(2), 154-171.

[10] Smedsrud, J., (2018). Mathematically gifted accelerated students participating in an ability group: a qualitative interview study. Frontiers in Psychology, 9, 1359-1359.

[11] Lee, N., and Horsfall, B., (2010). Accelerated learning: a study of faculty and student experiences. Innovative Higher Education, 35(3), 191-202.

[12] Siegle, D., Wilson, H. E., and Little, C. A., (2013). A sample of gifted and talented educators' attitudes about academic acceleration. Journal of Advanced Academics, 24(1), 27-51.

[13] Preckel, F., Schmidt, I., Stumpf, E., Motschenbacher, M., Vogl, K., Scherrer, V., and Schneider, W., (2019). Highability grouping: benefits for gifted students' achievement development without costs in academic self-concept. Child Development, 90(4), 1185-1201.

[14] VanTassel-Baska, J., (1992). Educational decision making on acceleration and grouping. Gifted Child Quarterly, 36(2), 68-72.

[15] Gallagher, S., Smith, S. R., and Merrotsy, P., (2011). Teachers' perceptions of the socioemotional development of intellectually gifted primary aged students and their attitudes towards ability grouping and acceleration. Gifted and Talented International, 26(1-2), 11-24.

[16] Troxclair, D. A., (2013). Preservice teacher attitudes toward giftedness. Roeper Review, 35(1), 58-64.

[17] Geake, J., and Gross, M. U. M., (2008). Teachers' negative affect toward academically gifted students. Gifted Child Quarterly, 52(3), 217-231.

[18] Gardner, H., (1987). The theory of multiple intelligences. Annals of Dyslexia, 37(1), 19-35.
[19] Zaretskii, V. K., (2009). The zone of proximal development. Journal of Russian and East European Psychology, 47(6), 70-93.

[20] Aronson, J., (2002). Improving academic achievement: impact of psychological factors on education (Ser. Educational psychology series). Academic Press. 